\title{
Optimization Of Nutrients for The Growth Of Scenedesmus Sp. By Response Surface Methodology
}

\author{
Vasumathi K K, Fenila F, Nithya E M, Ramakant Pandey, Premalatha M
}

\begin{abstract}
Microalgae, the photosynthetic microorganisms growing abundantly in various ecosystems are not just weeds but a potential source for sequestration of $\mathrm{CO}_{2}$. Biological sequestration of $\mathrm{CO}_{2}$ by microalgae is much more significant from the physical and chemical methods as it produces biomass (source of biofuels) apart from sequestering $\mathrm{CO}_{2}$.The growth of microalgae depends upon and requires optimum concentration of light intensity, temperature, nutrients, concentration of inoculum to produce higher yield of biomass as well its byproducts. The present study aims to optimize the nutrients using RSM for growth of microalgae, Scenedesmus sp, which was isolated locally. The other parameters such as light intensity $\left(160 \mu \mathrm{E} / \mathrm{m}^{2} / \mathrm{s}\right)$, temperature $\left(25^{0} \mathrm{C}\right)$ and light/dark cycle (12/12) were maintained constant to reveal the nutrient effect on the biomass growth. The nutrients studied were nitrate (urea (0-500 ppm)), phosphate (potassium dihydrogen phosphate (0-500 ppm)), and bicarbonate ((potassium hydrogen carbonate (0-2000 ppm)). Face Centered Central Composite Design (FCCD) of 15 runs was obtained using Design Expert 8.0.7.1 (Trail version). The higher yield of biomass was obtained at optimized nutrient concentrations of 0 ppm nitrate, 250 ppm phosphate, and 1000 ppm bicarbonate. The response equation (biomass yield) as a function of nitrate, phosphate and carbonate concentrations was obtained which helps to identify the effect of various composition. The RSM technique will help to identify the best combination of nutrients for the growth of Scenedesmus sp.
\end{abstract}

Keywords: carbonate, nitrate, phosphate, FCCD optimization.

\section{INTRODUCTION}

Microalgae serve as a source for $\mathrm{CO}_{2}$ sequestration, biofuel production, single cell protein, $\beta$-carotenes, phycocyanin, etc. They are preferred sources for protein as their production per acre is higher than the same from other sources like corn, wheat, and soybean [1]. Research on enhancing the lipid content of microalgae has gained more attention due to depletion of fossil fuels, rising demand and need for carbon neutral power sources $[1,2,3,4]$.

Revised Manuscript Received on December 05, 2019

* Correspondence Author

Vasumathi K K*, Department of Biotechnology, Kalsalingam Academy of Research and Education, Virudhunagar, India.

Fenila F, Department of Chemical Engineering, Indian Institute of Technology Bombay, India

Nithya EM, Department of Energy and Environment, National Institute of Technology Tiruchirappalli, India

Ramakant Pandey, Department of Energy and Environment, National Institute of Technology Tiruchirappalli, India

Premalatha M, Department of Energy and Environment, National Institute of Technology Tiruchirappalli, India
Apart from sequestration of $\mathrm{CO}_{2}$, they also provide the above valuable products. The $\mathrm{CO}_{2}$ sequestered by the microalgae are converted to carbohydrates through photosynthesis. The $\mathrm{CO}_{2}$ uptake studies are carried out either by supplying $\mathrm{CO}_{2}$ at known mass flow rate or by adding bicarbonate or carbonate salts [5,6]. Microalgae can grow in waste water utilizing the organic and inorganic nutrients in it. Thus pure water is not necessary for the cultivation of microalgae and used in aquaculture for feeding aquatic species [7].

Studies on growth of microalgae is carried out in a number of media like BB, BG, SE, N11, and KEP I, TAP, F/2, etc. The suitability of the medium and the optimum concentration of nutrients is species dependent $[7,8]$. The factors influencing the growth of microalgae include $\mathrm{pH}$, temperature, and nutrient concentration, intensity of light, light to dark cycle ratio $[2,9,10,11,12$, and 13].

The growth of microalgae increases with increasing concentration of nitrate, carbonate, and phosphate until an optimum level $[14,15,16]$. Hence, in order to identify the optimized concentration of nutrients (nitrate, phosphate and carbonate) for growth of Scenedesmus sp., response surface methodology is employed in this study.

\section{MATERIALS AND METHODOLOGY}

\section{A. Organism and growth conditions}

The Organism Scenedesmus sp was used and it was locally isolated and identified as Scenedesmus arcuatus var capitatus [17]. The experiment was carried out in a reactor geometry of surface area to volume ratio of the flat plate photo bioreactor was $52.8 \mathrm{~m}^{-1}$ and depth $0.06 \mathrm{~m}$. Under laboratory conditions, light intensity of $160 \mu \mathrm{E} / \mathrm{m}^{2} / \mathrm{s}$ and light/dark cycle of $12 \mathrm{~h} / 12 \mathrm{~h}$ was maintained. The cultures were manually stirred frequently to avoid settling.

\section{B. Analytical procedures}

The following methods were adopted for measurement of growth. The growth of microalgae was measured using Spectrophotometer at $440 \mathrm{~nm}$ [17]. The $\mathrm{pH}$ was measured using the digital $\mathrm{pH}$ meter. The cell count was measured using the Neubaeur hemocytometer [18]. The biomass was harvested by centrifugation at 10,000 rpm for 3 minutes in a centrifuge. 


\section{Optimization Of Nutrients for The Growth Of Scenedesmus Sp. By Response Surface Methodology}

The harvested biomass was transferred to a container of known weight $\left(\mathrm{W}_{1}\right)(\mathrm{g})$ and dried in a hot air oven at $60^{\circ} \mathrm{C}$ until it reaches constant weight $\left(\mathrm{W}_{2}\right)(\mathrm{g})$. The dry cell weight was estimated from the difference in above.

$$
\mathrm{DCW}=\mathrm{W}_{2}-\mathrm{W}_{1}
$$

The regression equation was obtained from calibration curve plotted between Wet weight ( $\mathrm{g} / \mathrm{L})$ Vs Dry weight $(\mathrm{g} / \mathrm{L})$ and was used for calculation of wet weight $(\mathrm{g} / \mathrm{L})$ and dry biomass $(\mathrm{g} / \mathrm{L})$ respectively.

\section{Response surface methodology (RSM)}

The RSM statistical tool is used to find the relationship of response variable with different nutrients and its concentration. Face-Centered Central Composite Design (FCCD)) was used in this presents study. Design Expert' software (Version 8.0.7.1, State-Ease Inc., Minneapolis, USA - Trail version) statistical package was used for the experimental design (Table 1).

\section{Data analysis}

The regression analysis of variance (ANOVA) was done using the Design Expert software. All of the experiments were carried out in triplicate, and the average value was recorded as the response. The quality of fit was expressed by the $\mathrm{R}^{2}$ value and the significance was assessed with an F-test.

Table1: Central composite design for nitrogen, phosphorous and bicarbonate source for growth of Scenedesmus sp.

\begin{tabular}{|c|c|c|c|c|}
\hline Run & $\begin{array}{c}\text { Factor 1: } \\
\text { Nitrogen } \\
(\mathbf{p p m})\end{array}$ & $\begin{array}{c}\text { Factor2: } \\
\text { Phosphorous } \\
(\mathbf{p p m})\end{array}$ & $\begin{array}{c}\text { Factor 3: } \\
\text { Bicarbonate } \\
(\mathbf{p p m})\end{array}$ & $\begin{array}{c}\text { DCW } \\
(\mathbf{g} / \mathbf{L})\end{array}$ \\
\hline 1 & 250 & 250 & 2000 & 0.38 \\
\hline 2 & 500 & 500 & 2000 & 0.35 \\
\hline 3 & 250 & 500 & 1000 & 0.49 \\
\hline 4 & 0 & 0 & 0 & 0.03 \\
\hline 5 & 250 & 250 & 0 & 0.32 \\
\hline 6 & 500 & 0 & 2000 & 0.27 \\
\hline 7 & 500 & 250 & 1000 & 0.58 \\
\hline 8 & 0 & 250 & 1000 & 0.55 \\
\hline 9 & 0 & 500 & 0 & 0.32 \\
\hline 10 & 500 & 0 & 0 & 0.35 \\
\hline 11 & 500 & 500 & 0 & 0.4 \\
\hline 12 & 250 & 0 & 1000 & 0.31 \\
\hline 13 & 0 & 500 & 2000 & 0.56 \\
\hline 14 & 0 & 0 & 2000 & 0.26 \\
\hline 15 & 250 & 250 & 1000 & 0.51 \\
\hline
\end{tabular}

\section{RESULTS AND DISCUSSION}

\section{A. Analytical results}

The experiment was conducted for 8 days and the absorbance was measured at 440nm using Hach DR-2800 spectrophotometer. The absorbance was found to increase with respect to time until it reached a peak value and then decreased. The $\mathrm{pH}$ was measured using $\mathrm{pH}$ meter. The $\mathrm{pH}$ was found to increase with growth. The initial $\mathrm{pH}$ was found to be lowest in $0 \mathrm{ppm}$ nitrate, $500 \mathrm{ppm}$ phosphate and $0 \mathrm{ppm}$ carbonate ( $\mathrm{pH} 6.62$ (increased up to 8.33). The highest initial $\mathrm{pH}$ was found in $500 \mathrm{ppm}$ nitrate, $0 \mathrm{ppm}$ phosphate and 2000 ppm carbonate( $\mathrm{pH} 8.36$ (increased up to 9.49). The number of cells of microalgae in the sample was estimated by Neubaer hemocytometer. The increase in number of cells was found to follow the same pattern as that of absorbance.

\section{B. Response surface methodology}

The one-factor analysis for the formulation of culture media is extremely time consuming [19]. Whereas, the employment of RSM is an accurate and further minimizes the error in less time. The statistical tool is successfully used in various fields of biotechnology, especially used for optimization in broad interval analysis [18].

A model equation was developed using the experimental response (biomass yield $(\mathrm{g} / \mathrm{L})$ ) in terms of nutrient concentrations (nitrate (ppm), phosphate (ppm), carbonate (ppm)).

$\mathrm{R}=0.045991+6.24194 \mathrm{E}-005 * \mathrm{~A}+1.40977 \mathrm{E}-003 * \mathrm{~B}+$ 4.00590E-004* C -8.74771E-007* A *B-2.99309E-007*A * $\mathrm{C}+2.45279 \mathrm{E}-008^{*} \quad \mathrm{~B} * \mathrm{C}+1.08159 \mathrm{E}-006 * \quad \mathrm{~A}^{2}$ $-1.71493 \mathrm{E}-006 * \mathrm{~B}^{2}-1.47663 \mathrm{E}-007 * \mathrm{C}^{2}$

Where, R-response (biomass yield $(\mathrm{g} / \mathrm{L})$, A- nitrate concentration (ppm), B - phosphate concentration (ppm), C carbonate concentration (ppm).

\section{ANOVA results}

The Analysis of Variance for the above model is tabulated in Table. 2. The high value of $F$ value, $P$ - value less than 0.05 indicates the effect of nutrients on the biomass growth and its significance. The predicted and adjusted values are in reasonable agreement which explains that there is no much difference between the predicted and actual values. Also, the $\mathrm{R}^{2}$ values are near to 1 thus the model is significant.

\section{Predicted vs actual}

Fig. 1 shows the plot between predicted and actual values of biomass yield $(\mathrm{g} / \mathrm{L})$. The actual biomass yield $(\mathrm{g} / \mathrm{L})$ range was from $0.030 \mathrm{~g} / \mathrm{L}$ to $0.58 \mathrm{~g} / \mathrm{L}$ whereas the predicted biomass yield range $(\mathrm{g} / \mathrm{L})$ was from $0.038 \mathrm{~g} / \mathrm{L}$ to $0.58 \mathrm{~g} / \mathrm{L}$. Since almost all points lie on the diagonal line, the values of predicted and actual values are in agreement with each other.

\section{E. Optimization values}

The contour plots on the response obtained from the experiment are given in Fig. 2 (2a, 2b, 2c). Fig. 2a shows the response at different concentrations of nitrate and phosphate at zero ppm 
Table 2: Analysis of Variance for the experimental model

\begin{tabular}{|c|c|c|c|c|c|c|}
\hline $\begin{array}{c}\text { Sum of } \\
\text { Square } \\
\text { s }\end{array}$ & df & $\begin{array}{c}\text { Mean } \\
\text { Square }\end{array}$ & $\begin{array}{c}\mathrm{F} \\
\text { Value }\end{array}$ & $\begin{array}{c}\text { P-Valu } \\
\mathrm{e} \\
\text { Prob> } \\
\mathrm{F})\end{array}$ & $\begin{array}{c}\text { Predict } \\
\text { ed } \\
\mathrm{R}^{2}\end{array}$ & $\begin{array}{c}\text { Adjust } \\
\text { ed } \\
\mathrm{R}^{2}\end{array}$ \\
\hline 0.29 & 9 & 0.032 & 52 & 0.0002 & 0.9769 & 0.9251 \\
\hline
\end{tabular}

of carbonate. Fig. 2b shows the response at different concentrations of phosphate and carbonate at zero ppm of nitrate. Fig. $2 c$ shows the response at different concentrations of nitrate and carbonate at zero ppm of phosphate. The plots show that the maximum yield is obtained at 0 and $500 \mathrm{ppm}$ nitrate, 250 ppm phosphate and 1000 ppm carbonate. Since the yield at $0 \mathrm{ppm}$ is equivalent to that at $500 \mathrm{ppm}$ nitrate, nitrate supplementation is not necessary for this species when light intensity of $160 \mu \mathrm{E} / \mathrm{m}^{2} / \mathrm{s}$ and temperature of $25^{\circ} \mathrm{C}$ is maintained.

The biomass productivity of Chlorella was found to be higher at $0.7 \mathrm{~g} / \mathrm{L}$ of sodium nitrate, whereas decreased when concentration is further increased to $1.4 \mathrm{~g} / \mathrm{L}$. Similarly, Chen et al. [20] studies showed that the higher biomass was obtained at an optimum sodium bicarbonate concentration was $1.2 \mathrm{~g} / \mathrm{L}$ and $1.5 \mathrm{~g} / \mathrm{L}$ respectively for Chlorella vulgaris.

The optimum concentration of nutrients will vary with different species. It was universally reported that $\mathrm{N}$ limitation will induce lipid accumulation. The optimized results were found to be $0 \mathrm{ppm}$ of nitrate, which may indirectly influence the lipid in Scenedesmus sp. Scenedesmus sp. can able to tolerate $80 \%$ of carbon dioxide and also a potential source for for producing lipid. Ren et al. [21] results are in agreement to the above statement. The Scenedesmus sp. at low nitrate concentration have accumulated $42 \%$ if lipid. Lari et al [22] reported that phosphorus concentration also affects the concentration have accumulated $42 \%$ of lipid. Lari et al [22]

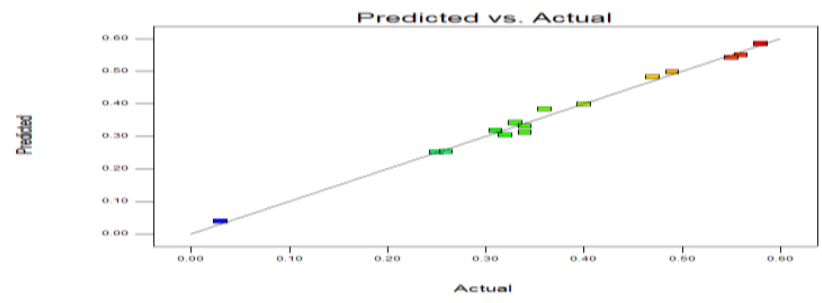

Figure 1: Predicted Vs Actual values of biomass yield (g/L) was found to be almost same

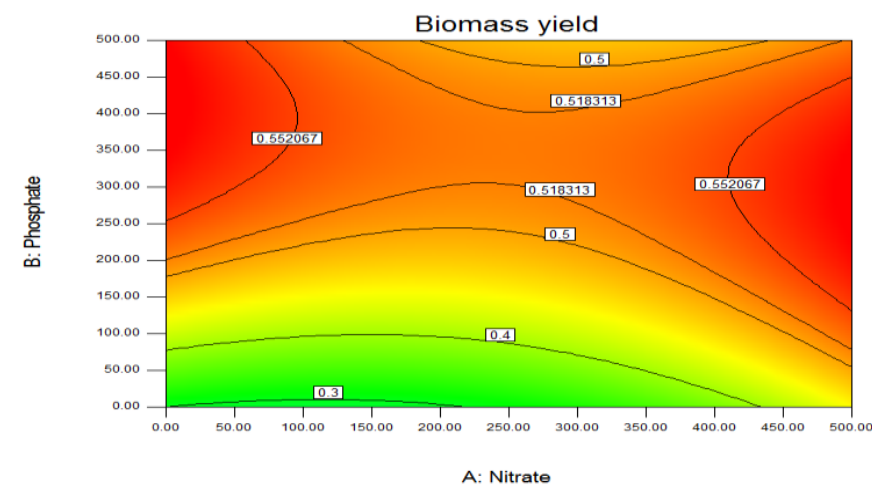

Figure 2 a Effect of nitrate and phosphate on biomass yield

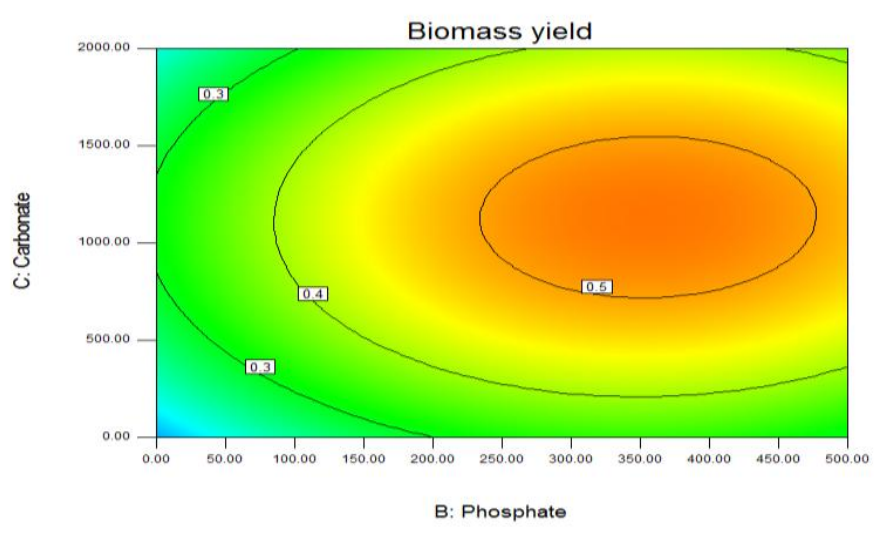

Figure 2 b Effect of phosphate and carbonate on biomass yield

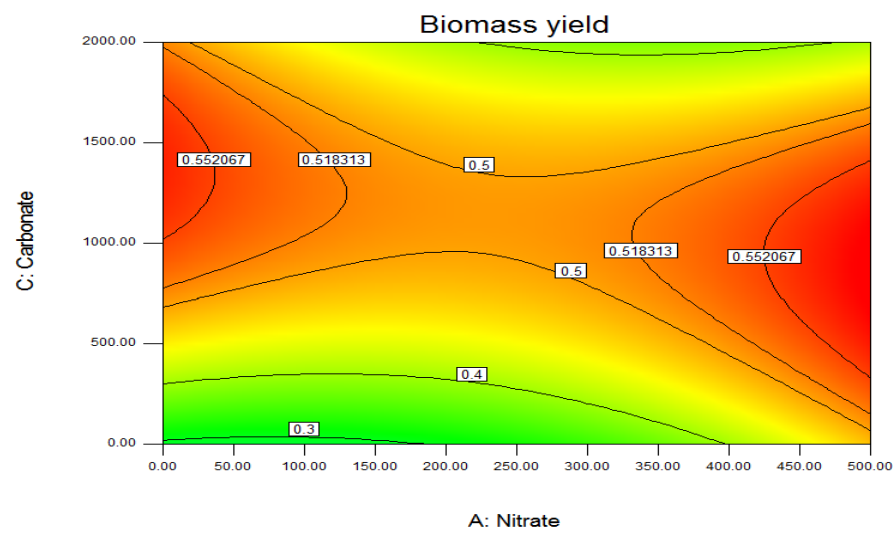

Figure 2 c. Effect of Nitrate and Carbonate on biomass yield

reported that phosphorus concentration also affects the composition of fatty acid of microalgae. Hence it is very much essential to do optimization studies based on the output.

\section{SUMMARY}

While cultivating microalgae, the main factors to be considered include light, temperature, nutrient concentrations. Since for large scale cultivation under ambient conditions the light intensity and temperature is varying so, the factor that can be varied is only the nutrients. Hence for a given light intensity and temperature, the effect of nutrients on growth of microalgae and the optimum concentrations of the same was obtained by the RSM. The use of sunlight reduces the expense for external light sources. The algal cultivation mediums available are composed of multiple components and make the preparation of the medium tedious. This study reveals that instead of cultivating microalgae in conventional algal growth mediums like BB, $\mathrm{BG}, \mathrm{TAP}$, etc. it is sufficient to cultivate algae with nitrate, phosphate and carbonate only as nutrients. Since the yield was higher at 0 and $500 \mathrm{ppm}$ nitrate, $250 \mathrm{ppm}$ phosphate and 1000 and 2000 ppm carbonate alone is sufficient for this species at light intensity of 160 
$\mu \mathrm{E} / \mathrm{m} 2 / \mathrm{s}$ and temperature of $250 \mathrm{C}$ is maintained. Similar result was obtained by Rajiv Chandra Dev Goswami et al, 2011 in Scenedesmus quadricauda where increase in urea (nitrate source) from $0.02 \mathrm{~g} / \mathrm{L}$ to $0.04 \mathrm{~g} / \mathrm{L}$ decreased the micro algal biomass productivity but at $0.06 \mathrm{~g} / \mathrm{L}$, the species was found to have higher biomass productivity. Also, since the carbonate uptake of this species is high, this is could be a potential species for $\mathrm{CO} 2$ sequestration. Earlier studies have proven that the deprivation of nitrogen source will enhance lipid accumulation in microalgae (Yanqun Li et al, 2008, Yadavalli et al, 2012). As this species is able to produce higher biomass even under deprivation of nitrogen source, the lipid content of this species is expected to be higher. There are still many unraveled products and microalgae available. The commercialization of this technology is still lagging due to its high cost. The optimization would help in to reduce the production cost.

\section{ACKNOWLEDGMENT}

We sincerely thank Department of Science and Technology (DST) for giving us an opportunity to work on the most important research area on microalgae for $\mathrm{CO} 2$ mitigation (DST/IS-STAC/ CO2-SR-12/07).

\section{REFERENCES}

1. Nirupama Mallick, Shovon Mandal, Amit Kumar Singh, Moumita Bishai, and Archana Dash, "Green microalga Chlorella vulgaris as a potential feedstock for biodiesel”, J Chem Technol Biotechnol, vol. 87, Jul 2011, pp. 137-145.

2. Ann-Ye-Liu, et al., "Identification of high-lipid producers for biodiesel production from forty-three green algal isolates in China", Progress in Natural Science: Materials International, vol. 21, 2011, pp. 269-276.

3. Arief Widjaja, "Lipid production from Microalgae as a promising candidate for biodiesel production", Makara, Teknologi, vol. 13(1), 2009, pp. 47-51.

4. K. Kalpesh, K. Sharma, Holger Schuhmann, and Peer M. Schenk, High Lipid Induction in Microalgae for Biodiesel Production, Energies, vol. 5, 2012, pp. 1532-1553.

5. Mijeong Lee Jeong, James M. Gillis, and Jiann-Yang Hwang , "Carbon Dioxide Mitigation by Microalgal Photosynthesis", Bull. Korean Chem. Soc, vol. 24(12), 2003, 1763. 2003.

6. A. Kumar, S. Ergas, X. Yuan, A. Sahu, Q. Zhang, J. Dewulf, F.X. Malcata, and $\mathrm{H}$. van Langenhove, "Enhanced $\mathrm{CO} 2$ fixation and biofuel production via microalgae: recent developments and future directions", Trends in Biotechnology, vol. 28(7), Jul. 2010: pp. 371-380.

7. M.K. Kim, J.W. Park, C.S. Park, S.J. Kim, K.H. Jeune, M.U Chang, and J. Acreman, "Enhanced production of Scenedesmus spp. (green microalgae) using a new medium containing fermented swine wastewater", Bioresource Technology, vol. 98, Aug 2007, pp. 220-2228.

8. Ángel Sánchez, Rocio Maceiras, Ángeles Cancela and Alfonso Pérez, "Culture aspects of Isochrysis galbana for biodiesel production", Applied Energy, vol. 101, Jan. 2013, pp. 192-197.

9. Celia. Y. Chen, and Edward G Durbin, "Effects of $\mathrm{pH}$ on the growth and carbon uptake of marine phytoplankton", Marine Ecology Progress Series, vol. 109, 1994, pp. 83-94.

10. Shih-Yuan CHEN, Li-Ying PAN, Min-Jhe HONG, and An-Chin LEE., "The effects of temperature on the growth of and ammonia uptake by marine microalgae", Botanical Studies, vol. 53, 2012, pp. 125-133.

11. Attilio Converti, Alessandro Alberto Casazza, Erika Rita Ortiz, Patrizia Perego, Marco Del Borghi, "Effect of temperature and nitrogen concentration on the growth and lipid content of Nannochloropsis oculata and Chlorella vulgaris for biodiesel production", Chemical Engineering and Processing, vol. 48, 2009, pp. 1146-1151.

12. A. E. Solovchenko, I. Khozin-Goldberg, S. Didi-Cohen, Z. Cohen, and M. N. Merzlyak, "Effects of light intensity and nitrogen starvation on growth, total fatty acids and arachidonic acid in the green microalga Parietochloris incise", J Appl Phycol, vol. 20, 2008, pp. 245-251.
13. T. Weisse, and P. Stadler, "Effect of $\mathrm{pH}$ on growth, cell volume, and production of freshwater ciliates, and implications for their distribution", Limnol. Oceanogr, vol. 51, 2006, pp. 1708-1715.

14. Rajasri Yadavalli, S. Ramgopal Rao, and C. S. Rao, "Lipid Accumulation Studies In Chlorella Pyrenoidosa Using Customized Photobioreactor- Effect of Nitrogen Source, Light Intensity and Mode of Operation", International Journal of Engineering Research and Applications (IJERA), vol. 2(3), May 2012, pp. 2446-24532.

15. C.R. Devgoswami, M.C. Kalita, J. Talukdar, R. Bora, P. Sharma, "Studies on the growth behavior of Chlorella, Haematococcus and Scenedesmus sp. in culture media with different concentrations of sodium bicarbonate and carbon dioxide gas", African Journal of Biotechnology, vol. 10(61), Oct 2011, pp. 13128-13138.

16. K.K. Vasumathi, M. Premalatha, P. Subramanian, "Parameters influencing the design of photobioreactor for the growth of microalgae". Sustainable and Renewable Energy Reviews, vol. 16, 2012, pp. 5443-5450.

17. K.K. Vasumathi, M. Premalatha, P. Subramanian, "Experimental studies on the effect of harvesting interval on yield of Scenedesmus arcuatus var. Capitatus", Ecological Engineering, vol. 58, 2013, pp. 13-17.

18. Chunmin Zhang, Yalei Zhang, Baolu Zhuang, and Xuefei Zhou, "Strategic enhancement of algal biomass, nutrient uptake and lipid through statistical optimization of nutrient supplementation in coupling Scenedesmus obliquus-like microalgae cultivation and municipal wastewater treatment", Bioresource Technology, vol. 171, Nov 2014, pp. 71-79.

19. A. Karemore, R. Pal, and R. Sen, "Strategic enhancement of algal biomass and lipid in Chlorococcum infusionum as bioenergy feedstock". Algal Research - Biomass Biofuels and Bioproducts, vol. 2, 2013, pp. 113-121.

20. C-Y. Chen, K-L. Yeh, H-M. Su, Y-C. Lo, W-M. Chen and J.S. Chang, "Strategies to enhance cell growth and Achieve High-level Oil Production of A Chlorella Vulgaris Isolate”. Biotechnol. Prog, vol. 26, 2010, pp. 679 $-686$.

21. H- Y. Ren, B- F. Liu, C. Ma, L. Zhao, and N- Q. Ren, "A new lipid-rich microalga Scenedesmus sp. strain R-16 isolated using Nile red staining: effects of carbon and nitrogen sources and initial $\mathrm{pH}$ on the biomass and lipid production", Biotechnology for Biofuels, vol. 6, 2013, pp. 143 153.

22. Z. Lari, N. Moradi-kheibari, H. Ahmadzadeh, P. Abrishamchi, N.R Moheimani, and M.A. Murry, "Bioprocess engineering of microalgae to optimize lipid production through nutrient management". J. Appl. Phycol, vol. 28(6), 2016, pp. 3235-3250.

23. Rajiv Chandra Dev Goswami, "Growth and lipid productivity of Scenedesmus spp under different concentration of urea", J. Algal Biomass Utln, Vol. 2 (4), 2011, pp. 42- 49.

24. L. Yanqun, H. Mark, W. Nan, Q.L. Christopher, and D. C. Nathalie, "Biofuels from microalgae", Biotechnol. Progress, vol. 24, 2008, pp. $815-820$. 